\title{
Study on Safety of Navigation Using Automatic Identification System for Marine Traffic area Case Study: Malacca Straits
}

\author{
Muhammad Badrus Zaman ${ }^{1}$
}

\begin{abstract}
International Maritime Organization (IMO) has recommended the implementation of Automatic Identification System (AIS) to improve the safety of navigation at marine traffic area. Based on regulation, IMO requires AIS to be fitted aboard all ships of 300 gross tonnage and upwards engaged on international voyages, cargo ships of $\mathbf{5 0 0}$ gross tonnage and upwards not engaged on international voyages and all passenger ships irrespective of size. The function of the AIS is to make communication between ship to ship and communication between ship to the port or land area. In this study, the study area is the Malacca Strait. Malacca Straits is the strait categorized as high risk level. Malacca straits is also busy area for maritime transportation because it is an area for international transportation lines. Many captains feel anxious and cautiously when passes through the strait. AIS receiver was used in this study which has been installed at Universiti Teknologi Malaysia by Kobe University Japan. Using AIS receiver, the current condition of the ship in the Malacca Straits area can be monitored properly. In addition, the data recorded on the AIS receiver can be used for research to enhance safety of navigation.
\end{abstract}

Keywords — automatic identification system (AIS), Malacca straits, marine traffic, safety of navigation

\section{INTRODUCTION}

$\mathrm{S}$ afety of navigation is very important issue in the maritime side. Implementation of AIS to enhace safety is recomenden by IMO regulation. Realtime condition was obtained by AIS in the traffic area. Management traffic has conducted using AIS data. Several ship's accidents are due to human errorr. To reduce it, and enhance safety of navigation in the marine traffic area, it is necessary to increase understanding of human factors aspects of navigational operation [1-2]. Moreover, equipment of navigation and other factors should operate properly.

The Malacca Straits is categorized a high-risk area for ship transportation. Based on survey, more than $80 \%$ of captains of ship responded that they are worried when passing the strait [1]. The objectives of International Maritime Organization (IMO) of implementing an automatic identification system (AIS) are to enhance the safety and efficiency of navigation, safety of life at sea, and protection of maritime environment [2-3]

For the application, AIS provides a means for ships to electronically send data including vessel identification, position, speed, and course with Vessel Traffic Services (VTS) stations as well as with other ships. AIS uses Global Positioning Systems (GPS) in conjunction with shipboard sensors and digital VHF radio communication equipment to automatically exchange navigation information electronically. Vessel identifiers such as the vessel name and VHF call sign are programmed in during initial equipment installation and

Muhammad Badrus Zaman, Departmen of Marine Engineering, Institut Teknologi Sepuluh Nopember, Surabaya 60111, Indonesia, Email :druz_zaman@ne.its.ac.id are included in the transmittal along with location information originating from the ship's global navigation satellite system receiver and gyrocompass. AIS is used by marine vessels in coordination with VTS to monitor vessel location and movement primarily for traffic management, collision avoidance, and other safety applications [4-6].

This paper is organized as follows. In the first section, we introduce the background of the research. In the second, we present a literature review. In this section, we have discussed the literature of this research and the originality of the research. In the third section, the investigation of AIS data in the Malacca Straits was conducted. In the fourth section, Result and discussion section. An analysis of traffic management using CPA and TCPA based on AIS data were explored. Finally, the conclussion of implemetation of AIS was presented.

\section{LITERATURE REVIEW}

Many studies on the application of AIS to evaluate and analysis traffic management to enhance safety for naviogation have already been conducted. Kobayashi et al [3] explored a guideline for ship evacuation in the case of a tsunami attack. They were used AIS data for an an evaluate of ships at Osaka Bay area, Japan [1-10].

Implementation of AIS for marine vessel emmision estimation was analyzed by Perez,MH et al [5]. In this paper, AIS was uses as source of data. Calculation of emmision for vessel operation was analyzed.

Zaman et al. [10] has been used the analytic hierarchy process (AHP) to analyze the implementation of the AIS in the Malacca Strait. In their study, a danger score assessment was established. The AHP is therefore used for evaluating the safety level in the Strait of Malacca. In this case, weighting factors are determined using the AHP. There are five evaluation criteria: the ship condition, human factor, environmental factor, machinery factor, and navigational factor. Each criterion divides into sub criteria and then sub-sub-criteria. 
Pitana et al. [6] determine the evacuation metodology. They have analyzed the evacuation of a large passenger vessel in the case of a pending tsunami using discrete event simulation (DES) method, which is considered to be a stochastic approach. In this paper, the authors used the AIS data to calculate the sea traffic in the area.

There is studies which has investigated an automatic identification system. Mou et al. [4] has been implemented AIS data for evaluating ship collision avoidance in busy waterways. A statistical analysis of ship collisions was carried out. In this paper, they have analyzed own ship and target ship by calculating CPA and TCPA. Decision making was taken based on CPA and TCPA. Risk assessment used samson model was carried out in this paper.

\section{AUTOMATIC IDENTIFICATION SYSTEM}

A. Study Area

Study area of this reserach is Malacca Straits. AIS receiver have installed at Universiti Teknologi Malaysia, Johor Malaysia. By using AIS, traffic data in the Malacca Straits area was obtained. Figure 1 shows map of study area.

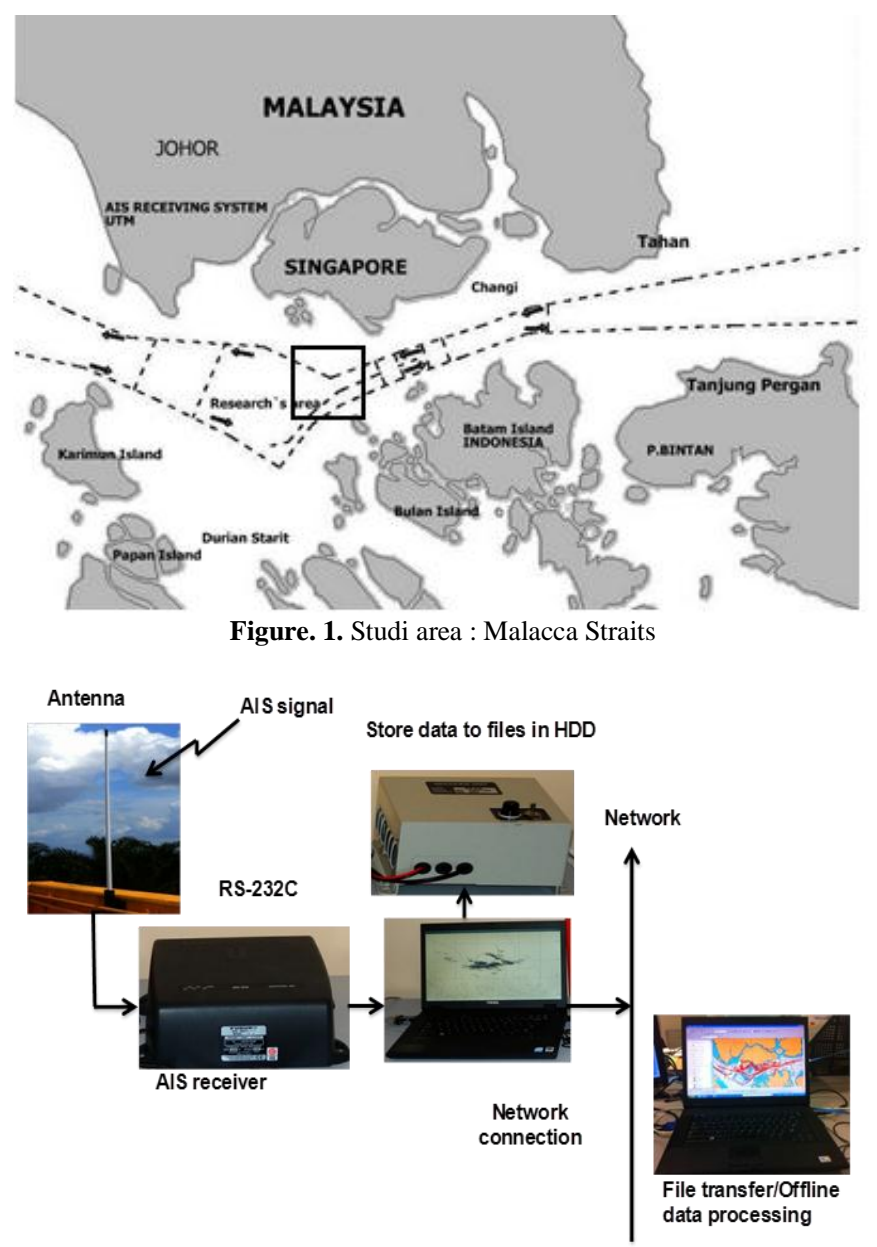

Figure. 2. AIS Receiver Installation

Figure 2 shows the AIS receiver system installation which was installed at Universiti Teknologi Malaysia. By using this installation, we could obtain AIS data and carry out to analyze traffic density, safety of navigation, risk assesment for traffic, danger score, safety index, emmision and all aspect related navigation.

\section{B. AIS Data and Processing}

AIS transmitters send data every 2 to 10 seconds depending on a vessel's speed while underway, and every 3 minutes while vessels are at anchor. These data include:

- The vessel's Maritime Mobile Service Identity (MMSI) - a unique, nine-digit identification number.

- Navigation status - "at anchor", "under way using engine(s)", or "not under command".
- Rate of turn - right or left, 0 to 720 degrees per minute.

- $\quad$ Speed over ground - 0 to 102 knots with 0.1 knot resolution.

- Position accuracy.

- $\quad$ Longitude and Latitude - to 1/10,000 minute;

- Course over ground - relative to true north to 0.1 degree.

- True Heading - 0 to 359 degrees from gyro compass.

- Time stamp - Coordinated Universal Time (UTC) time accurate to nearest second when this data was generated. ${ }^{8)}$

In addition, the following data are broadcast every 6 minutes whether underway or at anchor: 
- International Maritime Organization's (IMO) ship identification number - a seven digit number that remains unchanged upon transfer of the ship's registration to another country.

- International radio call sign, up to seven characters, assigned to the vessel by its country of registry.

- Vessel Name - 20 characters to represent the name of the vessel.

- Type of ship/cargo.

- Dimensions of ship - to nearest meter.

- Type of positioning system - such as GPS, Differential Global Positioning Systems (DGPS) or Long Range Navigation (LORAN) C.

- Location of positioning system's antenna onboard the vessel.

- Draught of ship - 0.1 meter to 25.5 meters.

- Destination - $\max 20$ characters.
- Estimated time of arrival (ETA) at destination UTC date hour: minute [8].

Based on AIS data, the traffic density in the Malacca Straits could be find on selected area in figure 1. Figure 3 shows traffic density per days. The highest traffic shown on 04 mei 2010 withn number of ship was 285 . The lowest traffic densityn shown on 26 mei 2010 with number of ships was 50 . Based on selected area, Figure 4 shows traffic density per hours. Ini this case, the highest data shown on $09.00 \mathrm{am}$. In this time, the number of ships was 35 . The lowest traffic density shown at $07.00 \mathrm{~m}$ pm with number of ships was 5 .

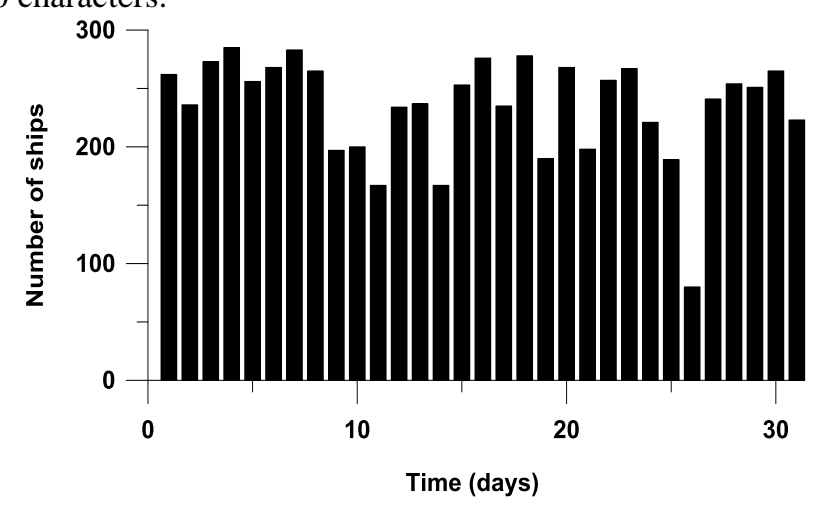

Figure. 3. Traffic density per day in the Malacca Straits

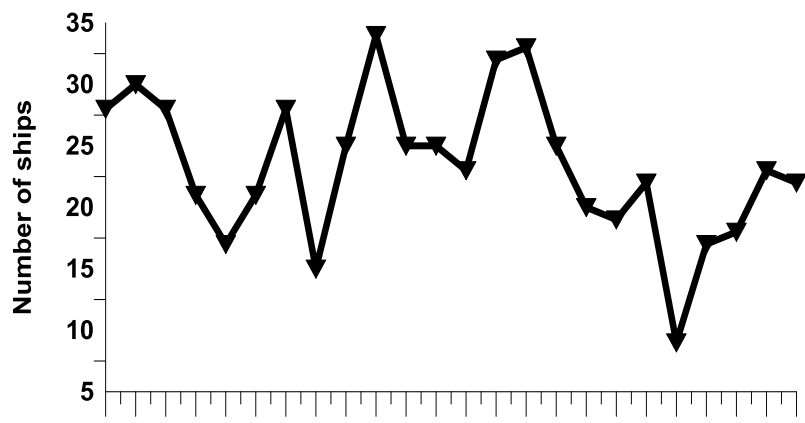

012344567891011121314151617181920212223

Time (hours)

Figure. 4. Traffic density per hour in the Malacca Straits

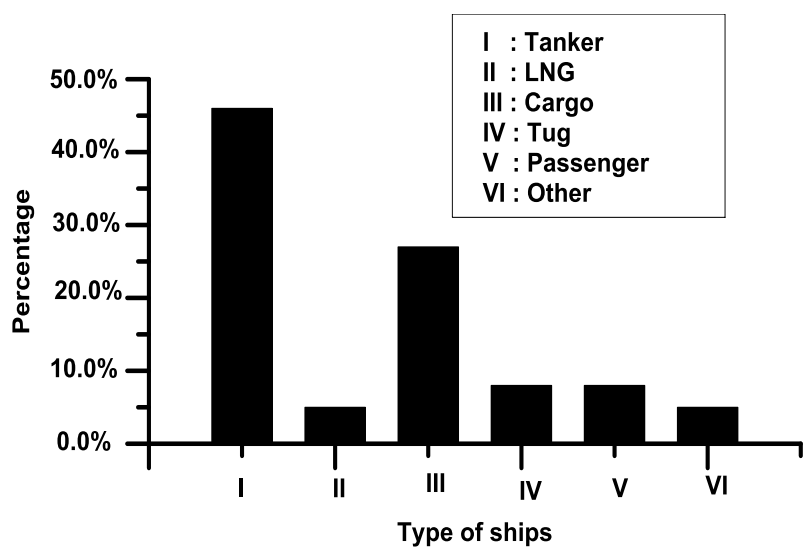

Figure. 5. Ship's population in the Malacca Straits 
Population of ship are shown in figure 5. Tanker's are highest population in the Malacca Straits were 45\%, cargo ships $25 \%$, tugs and passenger ships $15 \%$, LNG $5 \%$ and other ship $5 \%$.

\section{RESULT AND DISCUSSION}

\section{A. Encounter situation on board ship}

The Institute of Policy Studies (Singapore) and the International Maritime Organization (IMO) convened an international conference entitled "Navigational Safety and the Control of Pollution in the Straits of Malacca and Singapore.

The Malacca Straits, considered being the busiest shipping lane in the world. That area is a high-risk area for navigation. In this case, enhancing safety of navigation is very important to be conducted. AIS data is very useful tool to establish marine traffic safety.

Based on COLREG, the most important group of rules are the steering and sailing rules, which lay down the procedure to be followed when ships approach each other and there is a danger of collision. These situations are called close-quarters situations.

If two ships are approaching each other head on, both must alter course to starboard (or to the right) so that they pass each other port side to port side. Where a vessel is on the starboard hand of another, and steering a crossing course which may result in a collision, she has the right of way and should maintain her course and speed, the other vessel giving way to her. Where a vessel is on the port hand (side) of another, and her course, if she maintains it, may result in a collision, she is the giving way vessel and must alter course to avoid the other. But any ship overtaking another, i.e., approaching at any angle from two points $\left(22.5^{\circ}\right)$ abaft the beam on either side, must keep clear. When a vessel has the duty of giving way to another under the rules, she normally does so by altering course to pass astern of the other, and should make a clear and significant alteration of course in plenty of time to indicate to the other vessel that she is taking the appropriate action.

Based on COLREG rule 13, 14, 15, overtaking, head on, and crossing respectevely explored below:

\section{Overtaking situation}

1) Not with standing anything contained in the Rules of Part B, Sections I and II, any vessel overtaking any other shall keep out of the way of the vessel being overtaken.

2) A vessel shall be deemed to be overtaking when coming up with another vessel from a direction more than 22.5 degrees abaft her beam, that is, in such a position with reference to the vessel she is overtaking, that at night she would be able to see only the stern light of that vessel but neither of her sidelights.

3) When a vessel is in any doubt as to whether she is overtaking another, she shall assume that this is the case and act accordingly.

4) Any subsequent alteration of the bearing between the two vessels shall not make the overtaking vessel a crossing vessel within the meaning of these Rules or relieve her of the duty of keeping clear of the overtaken vessel until she is finally past and clear [2].

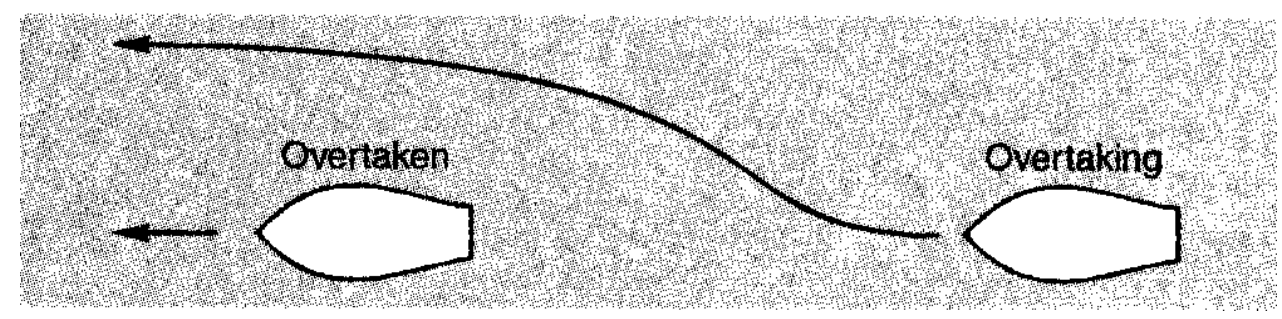

Figure. 6. Overtaking situation

\section{Head-on situation}

1) When two power-driven vessels are meeting on reciprocal or nearly reciprocal courses so as to involve risk of collision each shall alter her course to starboard so that each shall pass on the port side of the other.

2) Such a situation shall be deemed to exist when a vessel sees the other ahead or nearly ahead and by night she would see the mast head lights of the other in a line or nearly in a line andl or both sidelights and by day she observes the corresponding aspect of the other vessel.

3) When a vessel is in any doubt as to whether such a situation exists she shall assume that it does exist and act accordingly [2].

Crossing situation

When two power-driven vessels are crossing so as to involve risk of collision, the vessel which has the other on her own starboard side shall keep out of the way and shall, if the circumstances of the case admit, avoid crossing ahead of the other vessel [2].

Figure 6 shown the encounter ship situation based on COLREG. 

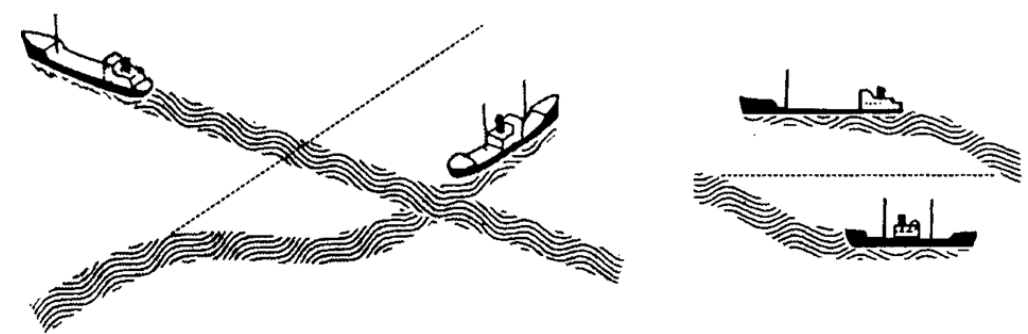

Figure. 7. Crossing situation

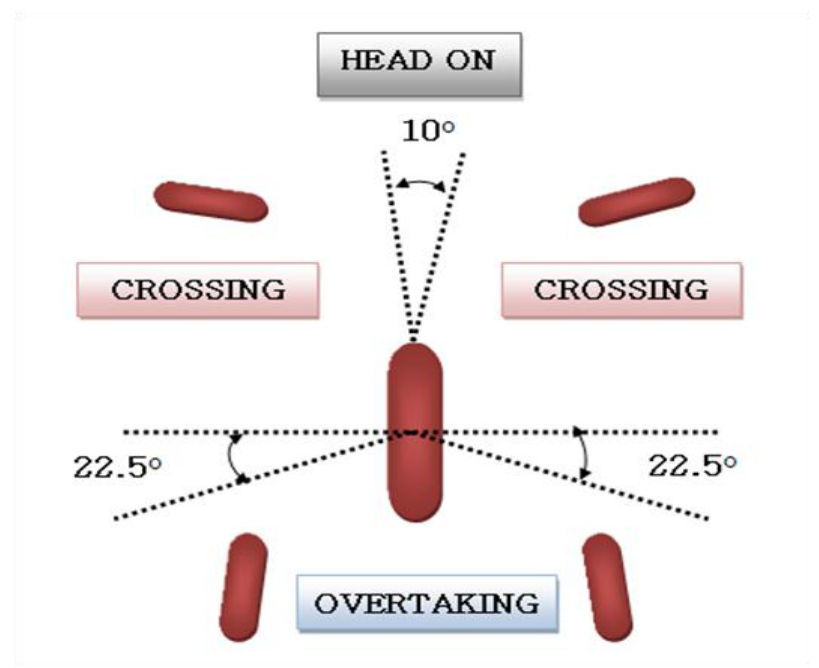

Figure. 8. Encounter types according COLREG

\section{B. Determining CPA and TCPA}

We have divided the traffic in the area into head-on situation, crossing situation and overtaking situation.

To determine the value of CPA (Closest point approach) and TCPA (Time to Closest Point Opproach), mathematical models are expressed below:

$$
\begin{gathered}
k=\frac{V_{1}}{V_{0}} \\
V_{01}=V_{0}\left[1+k^{2}-2 k \cdot \cos \left(C_{0}-C_{1}\right)\right]^{1 / 2} \\
C_{01}=C_{0}+\cos ^{-1}\left[\frac{V_{0\left(1-k \cdot \cos \left(C_{0}-C_{1}\right)\right.}}{V_{01}}\right]
\end{gathered}
$$

$$
C P A=D \cdot \sin \left(C_{01}-B\right)
$$

$$
T C P A=\frac{D \cdot \cos \left(C_{01}-B\right)}{V_{01}}
$$

where $V_{0}$ is velocity of own ship, $C_{0}$ is course of own ship, $V_{1}$ is velocity of target ship, $C_{1}$ is course of target ship, B is azimuth, D is distance between own ship and target ship.

In this research, value of CPA and TCPA are taken in the selected area as shown in Fig.1. The own ship and target ship taken in the busy area at $9.00 \mathrm{~h}$. As shown in Fig.4, at $9.00 \mathrm{~h}$ is largest number of ships.

Table 1.

Calculation of CPA and TCPA at the selested area.

\begin{tabular}{|c|c|c|c|c|}
\hline No & $\begin{array}{c}\text { CPA } \\
(\mathbf{n m})\end{array}$ & $\begin{array}{c}\text { TCPA } \\
(\mathbf{m i n})\end{array}$ & Basic risk & Dynamic risk \\
\hline 1 & 0.3 & 0.1 & $3.9 \mathrm{E}-08$ & $4.3 \mathrm{E}-09$ \\
\hline 2 & 0.6 & 0.2 & $3.6 \mathrm{E}-08$ & $7.6 \mathrm{E}-09$ \\
\hline 3 & -0.5 & 0.2 & $1.8 \mathrm{E}-07$ & $4.5 \mathrm{E}-08$ \\
\hline 4 & 0.3 & 0.6 & $1.9 \mathrm{E}-07$ & $4.7 \mathrm{E}-08$ \\
\hline 5 & -0.1 & 0.1 & $3.2 \mathrm{E}-08$ & $2.8 \mathrm{E}-08$ \\
\hline 6 & 0.2 & 0.1 & $2.2 \mathrm{E}-07$ & $7.4 \mathrm{E}-09$ \\
\hline 7 & 0.5 & 0.2 & $3.4 \mathrm{E}-08$ & $6.2 \mathrm{E}-08$ \\
\hline 8 & -1.7 & 0.3 & $2.1 \mathrm{E}-07$ & $3.6 \mathrm{E}-09$ \\
\hline 9 & -0.2 & 0.1 & $2.2 \mathrm{E}-08$ & $3.9 \mathrm{E}-07$ \\
\hline 10 & -0.7 & 0.3 & $3.3 \mathrm{E}-07$ & $4.2 \mathrm{E}-08$ \\
\hline
\end{tabular}


Table 1 shows the value of CPA, TCPA, basic risk and dynamic risk of ships in the Malacca Straits on May, 4, 2010 at $9.00 \mathrm{~h}$ for each of 10 tracks, which consist of the 5 highest basic risk and 5 lowest one. Those values are very useful to establish the decision making to enhance navigational safety.

As shown in table 4, CPA has value plus or minus. When the target ship is on the left side of relative motion trail, CPA is "positive". When the target ship is on the right side of the relative motion trail, CPA is "negative" [4].

\section{Decision Making}

In simple terms, AIS is technology to make visible to each other. As aid collision avoidance, it records the information of ship behavior, including the effects of human action and ship maneuverability. In this case, the collision avoidance is established based on AIS data by determining value of CPA, TCPA.

Based on calculation of CPA, TCPA and risk assessment, decision making is step which is very important to enhance navigational safety. Through dedicated VHF frequencies, AIS information is transmitted between vessels, from vessels to shore.

In practice, any collision-involved ship can increase the value of CPA by altering the course or changing the speed for anticollision. The success of collision avoidance maneuver can be assessed if CPA is larger than a certain value, for example 2 nautical miles (nm). Otherwise, if value of CPA is zero and no actions have been taken, the 2 ships will collide with each other.

\section{CONCLUSION}

Implementation of AIS is very usefull to enhance safety for ship's navigation. Communication ship to ship and port to ship could help crews of ship to keep good working on the ship.

The Malacca Straits as high density and busy area have relative high probability of collision. Human factors are high contributed of collision. By using AIS data, analysis of collision avoidance and related accident contribution were conducted. This study was presents the establishment of traffic management by determining CPA and TCPA based on AIS data.

This paper also shows how the AIS data can be used in the studies of ship collision in the Malacca Straits by determining risk for navigation.

In the analysis of collision avoidance, value of CPA and TCPA are very important value to establish collision avoidance in the Malacca Straits. In the collision avoidance analysis, dynamic risk is determined to improve the value of risk

Decision making could be conducted to enhance the safety of navigation in the Malacca Straits. Decision making is established based value of CPA, TCPA and risk assessment using AIS data.

\section{REFERENCES}

[1] Gran, S., " The Impact of Transportation on Wildlife in the Malacca Straits", TED Case Studies, 199, 9(3); No. 573.

[2] International Maritime Organization. "International Convention for the Safety of Life at Sea (SOLAS)", 1974.
[3] Kobayashi, E., Koshimura, S., Yoneda, S. "Guidelines for ship evacuation from tsunami attack", Proceedings of the International Society of Offshore and Polar Engineers (ISOPE), 2008, pp.68-70.

[4] Mou, J., Ligteringen, H., Gan, L., "A Study on collision avoidance in busy waterways by using AIS data," Journal of Ocean Engineering, Elsevier, 2010, pp.483-490.

[5] Perez, MH, Chang, R, Billing, R, "Automatic Identification System (AIS) Data Use in Marine Vessel Emmision Estimation, in Prosiding of conference of Automatic Identification System", 2012,pp:1-21

[6] Pitana, T., Kobayashi, E., "Assessment of Ship Evacuation Response to Pending Tsunamis", Journal of Marine Science and Technology, Vol.15, No.3, 2010, pp.242-256.

[7] $\mathrm{Qu} \mathrm{X,} \mathrm{Meng} \mathrm{Q,} \mathrm{Suyi} \mathrm{L,} \mathrm{"Ship} \mathrm{collision} \mathrm{risk} \mathrm{assessment} \mathrm{for} \mathrm{the}$ Singapore Strait. Els Sci Dir 43, 2011, pp:2030-2036.

[8] U.S. Coast Guard Navigation Center, U.S. Department of Homeland Security. “Automatic ID System”, 2009.

[9] Zaman, M.B., Kobayashi, E., Wakabayashi, E., Pitana, T., Maimun, A. "Fuzzy FMEA model for risk evaluation of ship collision in the Malacca Strait : Based on AIS Data", Journal of Simulation (JOS), vol.8, 2014, pp:91-104

[10]Zaman, M.B., Kobayashi, E., Wakabayashi, E., Pitana, T. Maimun, A. "Implementation of automatic identification system (AIS) for evaluation of marine traffic safety in the Malacca Strait using Analytic Hierarchy Process (AHP)", Journal of Naval Architects and Ocean Engineers (JASNAOE), vol.16, 2012 pp:141-153 